\title{
CONSIDERAÇÕES HISTÓRICAS SOBRE O ENSINO DE FILOSOFIA NO BRASIL DO PERÍODO COLONIAL ATÉ O SÉCULO XX
}

\author{
Angela Maria Souza Martins ${ }^{1}$ \\ UNIRIO
}

\begin{abstract}
RESUMO
Este artigo analisa historicamente como o ensino de Filosofia ingressou no contexto acadêmico brasileiro, a partir de um projeto político-pedagógico da Igreja Católica Apostólica Romana, criado no século XVI e que permaneceu até o século XX. Este ensino fez parte de uma estratégia educativa da Igreja para revitalizar a sua doutrina. Analisamos o tipo de concepção filosófica que embasou o ensino de Filosofia no contexto educacional brasileiro; uma concepção que tinha como parâmetro principal a interpretação tomista, segundo a escolástica portuguesa. Constatamos que a filosofia cultivada nos ginásios, liceus e faculdades até o século XX continuava predominantemente aristotélico-tomista. De acordo com os intelectuais da Igreja católica, a Filosofia deveria se ocupar da certeza, unidade e extensão do saber, mas a unidade e a certeza somente poderiam ser alcançadas por meio da filosofia aristotélico-tomista.

Palavras-chave: Ensino de Filosofia; História do Ensino de Filosofia; História da Educação Brasileira.
\end{abstract}

\section{HISTORICAL CONSIDERATIONS ON THE PHILOSOPHY EDUCATION IN THE COLONIAL PERIOD OF THE BRAZIL TO THE TWENTIETH CENTURY}

\begin{abstract}
This article historically examines how the Philosophy Education joined the brazilian academic context, from a political-pedagogical project of the Roman Catholic Church, created in the sixteenth century and remained until the twentieth century. This education was part of a church educational strategy to revitalize its doctrine. We analyzed the type of philosophy concept that based the Philosophy Education on the brazilian educational context; a concept that had as main parameter the thomist interpretation, according to the portuguese scholastic. We perceived the Philosophy cultivated in the gyms, high schools and colleges until the twentieth century remained predominantly aristotelian-thomist. In accordance with the Catholic Church intellectuals, the Philosophy should concern itself with the certainty, unit and knowledge extension, but the unity and the certainty could only be achieved through the aristotelian-thomistic philosophy.

Keywords: Philosophy Education; History of Philosophy Education; History of Brazilian Education;
\end{abstract}

\section{Introdução}

A história do ensino de Filosofia no Brasil vincula-se profundamente ao desenvolvimento da proposta político-pedagógica da Igreja. Desde o século XVI, a Filosofia é ensinada nos colégios e seminários católicos. Mesmo porque "a Igreja foi a única educadora [até] o século XVIII, representada por todas as organizações religiosas do clero secular e do clero regular que possuíam casa no Brasil" (LEITE, 1938, p.144) ${ }^{2}$. Por isso, para compreensão de como se desenvolveu o ensino de Filosofia no Brasil faz-se 
necessária uma análise, ainda que breve, do projeto político-pedagógico da Igreja no Brasil, dos seus primórdios, no século XVI, até o início do século XX.

$\mathrm{O}$ catolicismo que participou do processo de colonização foi o catolicismo da Contra-reforma. Naquele momento (século XVI) era necessária a confirmação da autoridade da Igreja, abalada com o movimento reformista que grassava na Europa, dividindo os cristãos em católicos e protestantes. A Igreja católica precisava revitalizar a sua doutrina, moralizar o seu clero e confirmar as suas tradições (HOORNAERT, 1977). Segundo a interpretação da Igreja, os movimentos reformistas dos séculos XV e XVI na Europa mergulharam o mundo na anarquia e na desordem. Por isso, fazia-se necessário restaurar a harmonia, a unidade e a universalidade do cristianismo.

No século XVI, com a expansão colonialista, as novas descobertas científicas e o surgimento de novas concepções filosóficas, como o racionalismo cartesiano, a Igreja vê abalada a sua hegemonia política e intelectual. $\mathrm{O}$ homem, impregnado pelo antropocentrismo, afastava-se de Deus, a sua vida pautava-se em bases naturalistas e materialistas. A inteligência guiava-se por razões "meramente humanas sem atender à hierarquia das coisas" (CURY, 1978, p.29).

Filosoficamente os séculos XVI e XVII caracterizavam-se pela descoberta cartesiana do "cogito" enquanto fundamento teórico que validava todo e qualquer conhecimento humano. A verdade fundamentava-se no "cogito", na razão humana, rompendo com a autoridade escolástica. Assim, "a razão promovida pelo próprio homem em valor absoluto se fez a única luz da sociedade, única mediadora entre os homens e Deus destronando a realeza social de Jesus Cristo" (CURY, 1978, p.33). Cai o teocentrismo, o centro do universo passa a ser o homem, que descobre o poder de dominar e controlar a natureza por meio de sua razão.

Dentro desse contexto, a Igreja busca revitalizar a sua doutrina, funda novas ordens, entre elas a Companhia de Jesus, em 1534, apregoa a volta à tradição e aos dogmas do catolicismo, amplia os horizontes de sua atuação com a finalidade de conquistar novas almas para a doutrina católica. Esse projeto de universalização da doutrina católica encontrou sua realização efetiva por meio de um projeto econômico e político que vigorava nos séculos XV e XVI na Europa, o expansionismo com a colonização no Oriente, África e América.

Assim, chega a Igreja ao Brasil, com um projeto político-pedagógico que atuaria por meio da catequese, da evangelização e da instrução. A ordem escolhida para essa missão foi a Companhia de Jesus. No dizer de Calógeras (1911), a Companhia de Jesus foi escolhida para a missão de catequizar e instruir as colônias portuguesas por ser uma congregação católica educadora e militante antirreformista e o "alto ideal que propugnava era a soberania do Papa e da fé católica" (CALÓGERAS, 1911, p. 4), ou seja, a Companhia de Jesus representava o ideal antirreformista, num período em que fervilhava o movimento reformista que contestava o poder e a autoridade da Igreja Apostólica Romana. Continuando, afirma Calógeras (1911), nesse período "no próprio seio das potências cathólicas (sic) existia poderosa corrente reformista, perigosíssima mesmo para a inteireza do dogma, pois visavam os novadores (sic) sanear a Egreja (sic) na cabeça e nos membros, desde o supremo poder pontifício até os últimos ramusculos (sic) da frondosa hierarchia (sic)" (CALÓGERAS, 1911, p.4). No interior desse projeto antirreformista é concebida a proposta educacional, de onde surge o ensino de Filosofia para o Brasil.

\section{A Companhia de Jesus e o ensino de Filosofia no Brasil}


Como já mencionamos anteriormente, a Companhia de Jesus ${ }^{3}$ representava uma força antirreformista, defensora do dogma e da hierarquia da Igreja Católica. Uma força que auxiliaria o governo português na ocupação das novas terras. Para Fernando de Azevedo (1964), Portugal encontrou nos jesuítas "um dos maiores e mais poderosos instrumentos de domínio espiritual e uma das vias mais seguras de penetração da cultura européia nas culturas dos povos conquistados, mas rebeldes, das terras descobertas" (AZEVEDO, 1964, p.503).

Por meio da catequese, a Companhia de Jesus cristianizaria os nativos e imporia uma ordem cristã naquela ordem irracional e primitiva. Dizia Anchieta (s.d.), "essa raça selvagem, sem a menor lei, perpetrava crimes horrendos contra os mandados divinos proferindo impunemente ameaças contínuas e altivos discursos" (ANCHIETA, s.d., p. 83). A proposta de cristianização incluía uma proposta de pacificação, de harmonização e de conversão não só religiosa, mas também de costumes.

Assim que chegam ao Brasil, os jesuítas fundam suas residências, conventos, seminários com a intenção de conquistar e dominar as almas dos nativos. É necessário ressaltar a preocupação primordial dos jesuítas era educação. No dizer de Leite (1938), ao falarmos das primeiras escolas brasileiras, estamos evocando a epopeia dos jesuítas no século XVI.

Os jesuítas fundaram várias escolas elementares, onde os filhos dos índios e dos colonos aprendiam a ler, escrever e contar. Por meio da instrução elementar, eles propagavam a doutrina católica. Para Fernando de Azevedo (1964), foi por meio dessas

escolas de ler e escrever, fixas ou ambulantes, em peregrinação pelas aldeias e sertões, que teve de começar a fundamentis (sic) a sua grande política educativa e, com elas é que se inaugurou, no Brasil e ao mesmo tempo na Europa, essa educação literária popular, de fundo religioso, organizada em consequência e sob os influxos das lutas da Reforma e da Contra-Reforma, para a propagação da fé (AZEVEDO, 1964, 508).

Mas não era somente no plano da instrução elementar que os jesuítas atuavam, a grande meta era a criação de escolas superiores para a constituição "de uma elite, culta e religiosa, que realizaria os objetivos místicos e sociais de Santo Inácio" (AZEVEDO, 1964, p.508).

$\mathrm{Na}$ primeira legislação escolar da Companhia de Jesus, as Constituições (aprovadas em 1558), constava a exigência de dois cursos, um de Letras, com duração de cinco anos, e um para estudos universitários de Filosofia e Teologia com duração de sete anos (MORAES FILHO, 1959).

Segundo Serafim Leite (1938), ainda no século XVI, os jesuítas criaram três cursos: Letras Humanas, Artes e Teologia, porque "num jesuíta a ciência é absolutamente quasi (sic) tão necessária como a virtude" (DEUSDADO, 1910, p.27).

Em 1556, fundou-se o colégio jesuíta da Bahia, que no dizer de Serafim Leite foi "a primeira Faculdade de Filosofia, primeira e única, no século dos quinhentos" (LEITE, 1938, v.VII, p. 46), a partir de então foram criados diversos colégios em várias partes do Brasil: em 1554, o Colégio Santo Inácio, em São Paulo; em 1567, o Colégio do Rio de Janeiro, onde a Filosofia começou a ser ensinada a partir de 1638. Este colégio foi "incorporado a seu correspondente em Coimbra, com o título de Real Colégio das Artes" (CAMPOS, 1978, p.43); em 1652, o Colégio de Nossa Senhora da Luz, em São Luís do Maranhão, neste mesmo ano o Colégio de Santo Alexandre, em Belém, no Pará; em 1654, o Colégio de São Tiago, em Vitória, no Espírito Santo. Em 1572, começa a primeira classe de Filosofia ou Artes, no colégio da Bahia. De acordo com Serafim Leite, "a primeira 
colação de grau de bacharel em Artes é de 1575 e, do ano seguinte, a licenciatura" (LEITE, 1965, p.59).

A finalidade desses cursos era não somente a formação de uma elite intelectual católica, como também a manutenção e a restauração dos princípios da cultura ibérica, constantemente ameaçadas pelas invasões, assim como pelas influências indígenas e africanas (AZEVEDO, 1964). No dizer de Fernando de Azevedo, "não fossem os jesuítas que se tornaram os guias intelectuais e sociais da Colônia, durante mais de dois séculos e teria sido talvez impossível ao conquistador lusitano resguardar dos perigos que a assaltavam a unidade de sua cultura e de sua civilização" (AZEVEDO, 1964, p. 510). Além disso, os jesuítas lutavam para manter a posse e a unidade do poder espiritual.

$\mathrm{Na}$ verdade, a vida intelectual da colônia girava em torno dos seminários e colégios católicos. Esta afirmação é corroborada por Fernando de Azevedo:

todos, pois, que se destinavam, na casa patriarcal, à carreira das letras ou à vida eclesiástica e monacal - e todas as famílias abastadas se desvaneciam de ter um filho letrado ou um filho padre - caíam naturalmente sob influência da educação jesuíta, em poder desses religiosos desde 1555, constituindo-se os instrumentos mais úteis de penetração de suas ideias e de seus métodos ( AZEVEDO, 1964, p. 514).

A educação católica pautava-se por uma perspectiva humanista e escolástica, que formava letrados e eruditos. Os jesuítas procuravam desenvolver em seus discípulos atividades literárias e acadêmicas que cumprissem o ideal de homem culto, para tal defendiam a preservação do dogma, da autoridade, da tradição escolástica e literária e rejeitavam a ciência e as atividades técnicas e artísticas. Consequentemente, a formação educacional católica não valorizou o espírito crítico, a pesquisa e experimentação.

Dentro desse espírito, moldou-se a educação brasileira, e, principalmente, o ensino de Filosofia. A filosofia que embasava o projeto político-pedagógico dos jesuítas era a interpretação tomista segundo a escolástica portuguesa.

A proposta pedagógica dos jesuítas estava sintetizada na Ratio Studiorum, uma espécie de código pedagógico, o primeiro esboço desse documento foi em 1586 e promulgou-se como Lei Geral da Companhia de Jesus, em 1559 (AZEVEDO, 1964). A Ratio Studiorum tinha como objetivo o conhecimento do aluno e a finalidade a atingir era a "glória de Deus". Sua proposta pedagógica comportava três cursos fundamentais: Letras Humanas, Artes ou Filosofia e Teologia. Estes três cursos formavam uma hierarquia rígida cujo ponto mais alto era a Teologia. Tanto Letras quanto Filosofia preparavam o estudante para o curso considerado o mais elevado, o de Teologia.

Segundo as diretrizes pedagógicas da Ratio Studiorum, o ensino de Filosofia, nos colégios e seminários católicos, devia estar embasado no estudo de Aristóteles e Tomás de Aquino. A Ratio Studiorum preocupava-se em preservar a doutrina aristotélico-tomista de interpretações não aprovadas pelos escolásticos do século XIII. O professor não deveria se afastar de Aristóteles e Tomás de Aquino, salvo raras exceções e não deveria discutir nada que fosse conflitante com a fé católica (CAMPOS, 1978).

A Filosofia ensinada no período colonial tem uma profunda influência do pensamento escolástico, principalmente do pensamento escolástico português, que tem como representante Pedro Fonseca; inclusive a obra de Pedro Fonseca, Comentários à Metafísica, foi a base de Cursus Conimbricensis, livro adotado no ensino de Filosofia no Brasil colonial. Este livro era uma espécie de enciclopédia pautada numa visão escolástica do século XIII. Além deste livro, outros eram adotados no curso de Filosofia, tais como: Cursus Philosophicus, de Arriaga, que chegou a Bahia em 1639; o Curso de Filosofia, de 
Antonio Vieira, que parece ter sido o primeiro livro escrito no Brasil entre 1629 e 1632; Cursus Philosophicus, de Domingos Ramos; Cursus Philosophicus, de Antonio Andrade e a Quaestione Selectiores de Philosophia Problematice expositae, de Luís de Carvalho (CAMPOS, 1978).

O curso de Filosofia pautava-se na leitura dos manuais citados acima. Os alunos deveriam reproduzir com exatidão os conhecimentos adquiridos por meio desses manuais, sempre com o cuidado de não exceder ou criticar o conhecimento exposto pelos comentadores de Aristóteles e São Tomás.

Segundo Fernando de Azevedo,

O curso de Filosofia e de Ciências, também chamado de Artes é dividido em três anos, tinha por fim a formação do filósofo, pelos estudos de Lógica, Metafísica geral, Matemáticas elementares e superiores, Ética, Teodicéia e das Ciências Físicas e Naturais, tomadas pela escolástica e estudada ainda a esse tempo como ciências constituídas definitivamente pelas especulações aristotélicas. Em Aristóteles, segundo os escolásticos; estava tudo: nada que investigar ou que discutir, só havia o que comentar (AZEVEDO, 1964, p. 519).

Os jesuítas preocupavam-se em perpetuar e resguardar a interpretação escolástica de São Tomás e Aristóteles. Dessa forma preservavam também a veiculação dos dogmas e dos princípios tradicionais da doutrina católica, pautadas na autoridade, no espírito conservador e na disciplina, com o intuito de preparar os estudantes de Filosofia para o curso de Teologia.

Pode-se afirmar que o conteúdo veiculado pelo ensino de Filosofia na fase colonial privilegiava algumas ideias fundamentais da doutrina tradicional católica, a hierarquização das ideias, a disciplina da razão e a sua submissão à fé e à concepção de ordem. Era a maneira encontrada pela Igreja de resguardar a concepção de mundo católica das correntes racionalistas e empiristas, que proliferavam nos séculos XVI, XVII e XVIII. Segundo Campos, "a escolástica no Brasil colônia é, assim, o reflexo da doutrina aristotélicotomista dos conimbricenses, cujo conteúdo é de natureza dogmática" (CAMPOS, 1968, p. 47).

O método utilizado nos cursos de Filosofia baseava-se em repetições diárias e semanais, feitas em casa ou na escola, quando os estudantes discutiam uns com os outros os pontos mais difíceis. A Ratio Studiorum também determinava desafios entre os alunos do mesmo nível e ordenava que se enviassem ao padre provincial composições ou dissertações para comprovar os estudos feitos.

Dentro dos princípios da Ratio Studiorum, segundo as interpretações aristotélicotomistas da escolástica portuguesa, o ensino de Filosofia permanece inalterado até o século XVIII.

Em 1759, devido à reforma realizada pelo Marques de Pombal, os jesuítas foram expulsos da colônia, fato que provocou algumas modificações no processo educativo da educação elementar, como também no ensino de Filosofia e Teologia. Nesse período foram fechados cerca de dezessete colégios e seminários "sem contar os seminários menores e as escolas de ler e escrever, instaladas em quase todas as aldeias e povoações onde existiam casas da Companhia" (AZEVEDO, 1964, p.539).

Em 1772, foi criado um fundo especial para financiar a reforma feita pelo Marques de Pombal, por meio da criação de um imposto, o subsídio literário, para contratar Professores Régios. Com esse subsídio foram criadas 358 vagas para Professores Régios e, um desses foi nomeado professor de Filosofia Racional e Moral, no Rio de Janeiro 
(ALMEIDA, 2003). A concepção filosófica que predominava era diferente da escolástica portuguesa, utilizavam Aristóteles de modo diferente da interpretação escolástica, mas este professor tornou-se suspeito diante da coroa portuguesa e foi envolvido na Devassa coordenada pelo vice-rei Conde Resende, em 1794, foi preso porque defendia ideias insurrecionais contra Portugal.

No final do século XVIII, em reação à corrente escolástica implantada por meio do ensino da Companhia de Jesus surge o movimento antiescolástico, iniciado em Portugal sob o governo de Pombal. Este movimento teve como elemento fundamental as Cartas de Verney, que foram a base da reforma da universidade em Portugal. Mas estas reformas não atingiram o Brasil de modo significativo, a nossa estrutura educacional não apresentou mudanças substanciais. No curso de Filosofia, a mudança observada foi o uso de um novo manual. Adota-se, a partir de então, o livro de Antonio Genovesi, as Instituições de Lógica, o Genuense, que passou a ser o livro oficial do ensino de Filosofia. Neste livro percebe-se a orientação aristotélico-tomista mesclada ao empirismo lockeano.

Nesse período, a estagnação da educação brasileira começou a provocar discussões, acirrando a luta pela implantação de uma universidade, no Brasil. Portugal proibia a instalação de qualquer instituição de nível superior na colônia. A partir do final do século XVIII, agravaram-se as lutas políticas no Brasil e eclodiram os movimentos libertários, profundamente influenciados pelas ideias iluministas. Essa nova concepção filosófica trouxe outra concepção de educação. Os conjurados mineiros, por essa época, elaboravam planos para a criação de uma universidade em Vila Rica (MORAES FILHO, 1959).

Mas os movimentos libertários fracassaram e com eles o sonho de mudanças educacionais. O Brasil entra no século XIX sem universidade e, os princípios do ensino de Filosofia continuaram, ainda, apoiados na doutrina aristotélico-tomista, porque, expulsos os jesuítas, outras ordens católicas, tais como franciscanos e carmelitas a atuar como pilares da educação no Brasil.

No século XIX, surgem esperanças de alterações no contexto cultural brasileiro, devido à instalação do reinado de D. João VI, no Brasil. Essa nova situação política promoveu algumas mudanças no campo da cultura. Foram criados a Imprensa Régia, a Biblioteca Nacional, um museu e algumas escolas de nível superior, o curso de Medicina, na Bahia e no Rio de Janeiro, a Escola Militar, a Escola Naval, etc.

Mas apesar da criação de algumas escolas superiores, a situação do ensino como um todo permaneceu inalterada. No caso da Filosofia continuou-se adotando o manual Geneuense. Contrário a adoção deste manual, o professor de Filosofia Silvestre Pinheiro Ferreira, membro da comitiva de D. João VI, fez-lhe sérias críticas e tentou com a publicação de seu livro ${ }^{4}$, afastar o compêndio oficial usado nas escolas brasileiras.

No período do Império acirraram-se os debates em torno da criação da universidade e do ensino superior de Filosofia no Brasil. Surgiram vários projetos que propunham a criação de cursos superiores e, principalmente, de uma universidade, onde existisse um curso de Filosofia.

Mas até meados do século XIX, não se cogitava da fundação de uma universidade no Brasil e, principalmente, de um curso superior de Filosofia. Este curso era visto como desnecessário naquele momento. Na Constituinte de 1823, declarava o Sr. Antônio Carlos R. de Andrade Machado: "o colégio filosófico não insta tanto à vista da necessidade que temos de magistrados e advogados" (PRIMITIVO, 1936-1938, p.71). A Filosofia continuou a fazer parte apenas das escolas secundárias e de cursos preparatórios para $\mathrm{o}$ ensino superior.

Questionando essa situação, dizia Tobias Barreto: "na verdade o que é a Filosofia entre nós? Simplesmente o nome de um preparatório que a lei diz ser preciso para fazer-se 
o curso de certos estudos superiores" (BARRETO, 1926, p. 343). A Filosofia era obrigatória nos liceus e nos ginásios do Império, onde se ministrava um ensino sem grandes novidades, no qual os velhos manuais ainda eram seguidos, principalmente aqueles fundamentados no tomismo.

No século XIX, os parcos estudos de Filosofia a nível superior eram dados exclusivamente, nas faculdades de Direito e nos seminários católicos. Estes eram os dois espaços onde se cultivavam estudos de cunho especulativo. $\mathrm{O}$ curso de Direito era um dos centros de formação de intelectuais, no século XIX e início do século XX. Nas palavras de Nelson Werneck Sodré, os cursos de Direito

forneceram, como era sua finalidade, conhecimentos que permitiam a atividade ligada ao Direito, mas forneceram paralelamente - e até o fim da fase de que nos ocupamos, unicamente - aqueles conhecimentos ainda que em nível rudimentar, que seriam fornecidos adiante, por centros especializados de estudos, e, bem mais adiante, pelas Faculdades de Filosofia, isto é, o saber universal, humanístico, filosófico - com alguma licença nessas qualificações. De sorte que os bacharéis não se habilitavam apenas ao exercício profissional, mas às letras, ao jornalismo, à política, ao magistério, sem falar nas funções públicas (...) (SODRÉ, 1976, p. 37-38).

A Filosofia cultivada nos ginásios, liceus e faculdades de Direito durante o século $\mathrm{XX}$, continuava predominantemente tomista. Isto porque se recrutavam os intelectuais formados em Filosofia nos seminários e muitos iam estudar em faculdades católicas europeias, como em Louvain, na Bélgica. Alguns fatos ocorridos no século XIX corroboram essa afirmação. Em 1867, num concurso para o ensino de Filosofia no Ginásio Público Pernambuco, o professor José Soriano de Souza, tomista, autor da obra intitulada "Compêndio de Filosofia, ordenado segundo os princípios e métodos de Santo Tomás de Aquino", venceu o concurso, que eliminou Tobias Barreto. O professor José Soriano de Souza cursou Filosofia, em Louvain, Bélgica e era também professor de Direito Público e Constitucional na Escola de Direito, de Recife.

Em 1875, Sílvio Romero, seguidor do evolucionismo, foi derrotado no concurso para o ensino de Filosofia do Colégio das Artes de Recife, pelo professor Antônio Luís de Mello Vieira, tomista, autor da tese "Da interpretação filosófica na evolução dos fatos históricos", onde usa a técnica da argumentação silogística, apoiando-se, principalmente, em Santo Agostinho e São Tomás de Aquino, para provar que "a providência divina e a liberdade humana são causas de todos os fatos históricos" (CAMPOS, 1968, p.66).

A doutrina aristotélico-tomista embasava o ensino de Filosofia não só nas escolas católicas, como também nas escolas públicas estatais. Mas é preciso ressaltar que, em alguns momentos históricos, a hegemonia filosófica do tomismo defronta-se com outras correntes filosóficas. Nos meados do século XIX, foram introduzidas no Brasil ideias positivistas e evolucionistas, que tiveram ampla penetração na educação.

O positivismo embasou doutrinariamente uma significativa parcela do movimento militar que implantou a República, no Brasil. As ideias positivistas fomentaram a discussão sobre a possibilidade de uma Estado laico, o que acarretaria a criação de escolas públicas estatais com o ensino laico. Porém, até então, não só a Filosofia, mas a educação em geral era ministrada, quase que exclusivamente, de acordo com uma orientação confessional. Assim, as ideias positivistas tornaram-se uma ameaça para a educação católica. 
Ressaltamos que a Igreja até o período da monarquia vinculava-se ao Estado por meio do sistema de padroado. Neste sistema, a igreja católica ficava sob a proteção do Estado e o catolicismo era considerado a religião oficial e a única permitida pelo Estado. $\mathrm{O}$ governo era civil e religioso, ou seja, os governantes detinham o poder político e religioso; eles poderiam criar ou vetar a instalação de novas ordens religiosas e escolher quem dirigiria as dioceses (HOORNAERT, 1977).

A difusão de ideias que preconizavam o laicismo tornou-se uma ameaça para a Igreja em termos político, econômico e cultural. Com o advento da República, a vitória das ideias liberais e positivistas e a proclamação do Estado laico, os católicos passaram a buscar a hegemonia no plano cultural.

A partir de então, a Igreja católica passou a preocupar-se mais agudamente com a ocupação de espaços culturais e, em 1908, criou a primeira faculdade de Filosofia, a Faculdade de Filosofia e Letras de São Bento, iniciativa de D.Miguel Kruse, abade do Mosteiro de São Bento, em São Paulo. Segundo D. Odilão Moura, a intenção do abade era ver "a juventude católica universitária formada nos princípios da fé, para que ela fosse mais esclarecida e mais preparada na refutação dos erros filosóficos que a ameaçavam" (MOURA, 1978, p.143).

Mas não devemos esquecer que apesar da influência exercida no movimento republicano e em alguns setores da educação, como, por exemplo, no ensino de Ciências da Natureza e da Matemática, o positivismo não conseguiu abalar significativamente a forte influência da orientação tradicional católica no ensino de Filosofia.

A Faculdade de Filosofia e Letras de São Bento veio a ser mais um foco de irradiação da doutrina tradicional da Igreja, o tomismo. D. Miguel Kruse recorreu ao neotomista, cardeal Mercier, para ajudá-lo na tarefa de instalação de um instituto superior. O cardeal enviou monsenhor Charles Sentroul ao Brasil para auxiliá-lo nessa tarefa. Monsenhor Charles Sentroul era considerado conhecedor de Kant e São Tomás de Aquino. $\mathrm{Na}$ inauguração da faculdade proferiu uma conferência, em que disse:

a filosofia tem um tríplice papel: $1^{\circ}$ ) um papel próprio mas preliminar e, neste sentido, negativo: o de restabelecer o valor objetivo do conhecimento; $2^{\circ}$ ) um papel próprio e positivo, o de constituir, sob forma de metafísica, a síntese superior do saber; $3^{\circ}$ ) e também um papel positivo e auxiliar de submeter à metafísica, para as beneficiar, com a sua unidade sistemática, as ciências particulares.No seu primeiro papel, a filosofia ocupa-se especialmente da certeza do saber, no segundo da sua unidade, no terceiro - mas desta vez em colaboração com as ciências - da sua extensão. E como a certeza é por si mesma uma unidade (...) pode exprimir-se o papel da filosofia nestas palavras: é a ciência que completa a unidade do saber (SENTROUL, 1909, p. 234).

De acordo com os intelectuais vinculados a Igreja católica, essa unidade do saber somente poderia ser realizada pela filosofia aristotélico-tomista, porque acreditavam ser esta a filosofia verdadeira. Segundo a visão do Monsenhor Charles Sentroul, a Filosofia deveria estabelecer o valor objetivo do conhecimento e, enquanto metafísica realizar a síntese superior do saber. A Filosofia deveria se ocupar da certeza, unidade e extensão do saber. Para tal empreendimento poderíamos utilizar teorias filosóficas modernas, mas estas teorias não podiam colocar em cheque ou contestar a filosofia aristotélico-tomista, pois para esses intelectuais somente importava a verdade oriunda das teses de Aristóteles e São Tomás de Aquino (SENTROUL, 1909). 
Esse breve esboço histórico nos permite afirmar que o ensino de Filosofia no Brasil, do século XVI ao século XX, foi orientado de acordo com os princípios da proposta político-pedagógica da Igreja católica. Entre as características desta proposta educacional, destacam-se o privilégio atribuído aos estudos de cunho especulativo e a escolha do embasamento teórico aristotélico-tomista. Tais preocupações remontam a raízes antropológicas e ontológicas da doutrina cristã.

A explicação, ainda que breve, desses dois aspectos ressaltados acima possibilitará lançar luz sobre os princípios teórico-ideológicos que orientaram o ensino de Filosofia no contexto educacional brasileiro.

\section{A importância dos estudos especulativos para a educação católica}

Segundo a doutrina católica, "o homem é um ser espiritual, criado por Deus (...) composto de corpo e alma" (CURY, 1978, p. 46) e distingue-se dos demais animais pela sua racionalidade. A dupla composição do ser humano lhe possibilita o desenvolvimento de atividades corporais e espirituais, sendo que as primeiras deve se submeter às segundas. Tanto a vida quanto as faculdades humanas são concebidas a partir de uma visão hierárquica de princípios. Assim, "a vida vegetativa subordina-se à sensitiva, esta a vida racional, a racional à vida espiritual" (CURY, 1978, p. 55). Ou seja, as questões intelectuais são hierarquicamente superiores aos aspectos físicos e as questões morais e religiosas são superiores as questões intelectuais. Assim, a educação deve seguir esta hierarquia.

Acatando esses princípios, compete à educação o desenvolvimento intelectual, moral e religioso. A educação seria

a consciência que o ser humano deve ir adquirindo de sua destinação espiritual, através do uso ordenado das faculdades no domínio dos espíritos, através de hábitos salutares e da preparação do espírito para o mundo da graça, sob o influxo da lei eterna, tornando o homem apto a viver em sociedade ( CURY, 1978, p. 55)

No processo educacional, a formação intelectual pautada nos estudos especulativos tornase fundamental porque possibilita a ordenação das ideias, tanto no plano do conhecimento científico quanto no do conhecimento humanístico e, assim, podem-se atingir as verdades fundamentais. Estas verdades são "os primeiros princípios que ensinam o que é o homem, de onde vem e para onde vai" ( CURY, 1978, p.56) . Segundo a Igreja, a racionalidade iluminada pela graça descobre a ordem de tudo e Deus é a fonte do ser (CURY, 1978).

Atribui-se aos estudos de cunho especulativo a função de ordenar as ideias e aproximar o home de seu fim último, que é a vida espiritual. Nesse sentido, a Filosofia, considerada como um saber eminentemente especulativo que cultiva os princípios imutáveis, perenes e universais, tornase fundamental para a educação e para a doutrina católica. Ela possibilita, assim, a ordenação e a hierarquização das ideias.

\section{A escolha da doutrina aristotélico-tomista para guiar o ensino de Filosofia}

Segundo a concepção tradicional católica, a compreensão dos problemas fundamentais, tanto em termos teóricos quanto práticos, colocados ao longo da história, somente seria possível à luz de uma Filosofia única e certa (FRANCA, 1978). Deve-se 
partir de verdades inabaláveis que possam ser a base e o ponto de partida das investigações filosóficas, porque a razão deve buscar a verdade e o caminho único e certo que lhe auxilie a distinguir o erro e a verdade, por isso deve-se buscar a Filosofia. Para tal há três critérios fundamentais: o especulativo, o prático e o histórico (FRANCA, 1978).

O primeiro critério, o especulativo, é teórico e racional e orienta-se pela evidência, pois tudo que se fundamenta na contradição conduz ao erro, por isso a inteligência deve seguir uma lógica severa e sã que pode "desfiando as conclusões das premissas ou remontando dos consequentes aos antecedentes, desvendar o sofisma", seguindo esta lógica chega a verdade (FRANCA, 1978, p.329)

O segundo critério é de caráter prático e baseia-se nas questões morais dos sistemas filosóficos. Segundo Franca,

toda interpretação sintética do universo no domínio especulativo comporta no campo da ação uma série de aplicações práticas, um sistema moral que, desenvolvido cedo ou tarde pela lógica irresistível dos fatos , atesta o valor das ideias de que deriva, como a qualidade dos frutos abona a árvore que os produziu. Qualquer filosofia que logicamente importe a destruição do direito e da moral, a extinção da virtude e do heró́smo, a dissolução da família e da sociedade não é verdadeira (...) (FRANÇA, 1978, p. 329).

O terceiro critério, o histórico, faz a distinção entre a Filosofia e as Filosofias. Assim é considerada a Filosofia, aquela que segue seu curso com segurança, enquanto que as Filosofias são temporárias e, algumas se baseiam nas contradições, assim, de acordo com os intelectuais tradicionais da Igreja católica, a "doutrina verdadeira é perene e progressiva nos seus princípios fundamentais, certos e indestrutíveis, progressiva nas conclusões que deles podem derivar (...)" (FRANCA, 1978, p.329). Para esses intelectuais, a Filosofia deve sempre contribuir para atingir a verdade perene e lutar contra falsos sistemas.

Todos esses critérios seriam cumpridos, segundo a visão tradicional católica, por uma única doutrina, a aristotélico-tomista. Esta seria a Filosofia genuína, pois não sofreria as contingências do espaço e do tempo como as demais Filosofias. Na doutrina aristotélico-tomista estariam ainda os caminhos melhores para a destruição dos erros e a solução dos problemas sociais. Porque esta doutrina era considerada aquela que propalava as verdades de acordo com a revelação de Deus e dos escritos dos Santos Padres, assim defendia os princípios da reta razão.

Segundo Padre Werner (In: MOURA, 1978), a escolástica mantinha a paixão pela verdade, por isso ela enfrenta

tudo que pode velar, alterar, adulterar, dissimular a verdade (...) Ela é ciência, não é arte, ela é estudo não é divertimento, ela escreve a explicação do universo,não como Bergson, um romance do universo, ensina o que observa, não como Fechner ou o Send-Avest, o que imaginou, diz o que é, não o que seria bonito que fosse (WERNER, In: MOURA, 1978, p.148)

Entre os séculos XIX e XX persiste a defesa da doutrina aristotélico-tomista, porque esta cultiva uma verdade inabalável, pautada em princípios perenes, imutáveis e universais. Ela tornou-se a base teórica da proposta para o ensino de Filosofia, no contexto educacional brasileiro. Podemos afirmar que os princípios aristotélico-tomistas foram 
fundamentais para a consolidação da hegemonia espiritual e cultural da Igreja católica no contexto social brasileiro.

\section{Considerações Finais}

Transformada em Filosofia, a doutrina aristotélico-tomista transformou-se numa espécie de escudo para combater outras correntes filosóficas. Tornou-se a expressão da verdade absoluta, os seus princípios teóricos deveriam ser, necessariamente, o ponto de partida da investigação filosófica tanto da realidade social e histórica como das demais correntes filosóficas.

Esse dogmatismo influenciou a orientação do ensino de Filosofia no Brasil. A Filosofia desenvolveu-se tal como uma religião, cultivando princípios imutáveis, mostrando-se ao mundo como verdade eterna. As interpretações aristotélico-tomistas assumiram no contexto cultural brasileiro o papel de filosofia da ordem estabelecida, como um dique destinado a conter a penetração de teorias que pudessem trazer qualquer base de contestação à reflexão filosófica institucionalizada. Transformações e mudanças da realidade eram consideradas, pelos intérpretes dessa doutrina, como sinal de desagregação e crise, ameaças ao cultivo de princípios e valores adequados a uma ordem social e moral estável.

Como já discutimos anteriormente, a realidade, segundo os pressupostos aristotélico-tomistas, deveria corresponder à ordem da razão, ou seja, aos princípios perenes, imutáveis e absolutos estabelecidos a priori pela razão. Assim, o pensar perene ordenaria e determinaria a realidade; os produtos do pensar adquiriram autonomia e passaram a ser a própria expressão da realidade. Segundo Marx e Engels, a filosofia especulativa "estava na obrigação de despojar todas as questões da forma que lhes dava sentido humano e traduzi-las na forma da razão especulativa, de transformar a questão real em uma questão especulativa para poder respondê-la" (MARX e ENGELS, 1973, p.106).

A Filosofia ensinada nas academias e colégios brasileiros, do período colonial até as décadas iniciais do século $\mathrm{XX}$, salvo raras exceções, foi responsável pelo aprofundamento da dicotomia ser/pensar. Dicotomia que acarreta consequências de ordem teórica - ontológica e epistemológica - e de ordem prática - política.

Em termos ontológicos, significa que o fundamento de uma determinada realidade, ou seja, o seu ser expressa-se por conceitos que são produzidos exclusivamente por operações racionais desvinculadas da realidade sócio-histórica, desta premissa decorre a seguinte consequência epistemológica: somente podemos conhecer a realidade por meio de princípios perenes e imutáveis estabelecidos a priori pela razão.

Consideramos que a Filosofia não se esgota nas teorizações de cunho ontológico e epistemológico. Ela tem ressonância de ordem prática e política. De acordo com Gramsci uma concepção de mundo ou Filosofia responde a problemas que são colocados por um contexto histórico e social, por isso ele questionava: "como é possível pensar o presente, e um presente bem determinado, com um pensamento elaborado em face de problemas de um passado frequentemente bastante remoto e superado?" (GRAMSCI, 2001, p.95). Uma Filosofia não é simplesmente um conjunto conceitual, ela expressa normas de comportamento e conduta de um determinado contexto histórico, assim nela se reúnem elementos teóricos e de ordem prática que redundam numa orientação política.

Assim, as proposições de ordem ontológica e epistemológica conduzem a consequências de ordem prática, a defesa da doutrina aristotélico-tomista conduziu para a defesa de uma realidade regida por princípios sociais, morais e políticos perenes e estáveis, de modo que as mudanças e transformações fossem rechaçadas. O ensino de Filosofia, no 
Brasil, entre os séculos XVI e os primórdios do século XX, viveu imerso em abstrações que impossibilitava a compreensão da realidade de modo dinâmico e contraditório. Concordamos com Gramsci, quando ele afirma que:

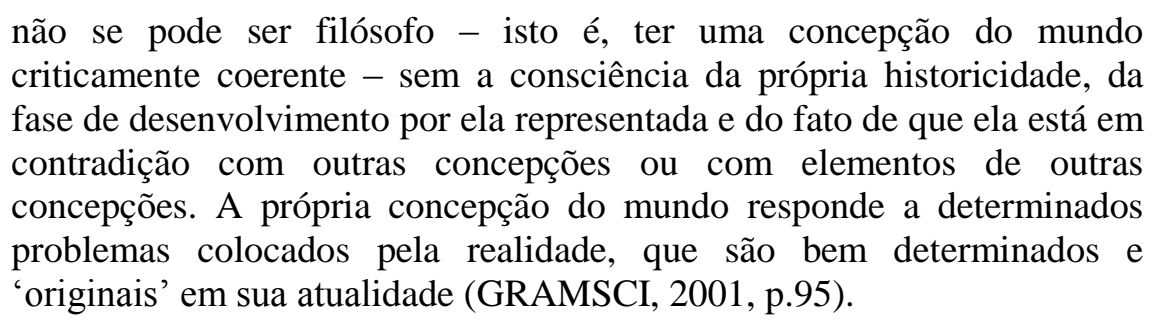

Pensamos que o ensino de Filosofia se fossilizou ao ter como guia uma orientação filosófica que desconsiderou a historicidade, que colocou o viver como algo estranho ao filosofar. Pensar e ser são aspectos distintos, mas estão vinculados de uma maneira dialética e histórica. Pois aquele que pensa não é um ser etéreo destacado da realidade histórica, mas um ser que se constitui num determinado contexto histórico e social.

\section{Referências}

ALMEIDA, Anita Correia Lima de. Notas sobre a Reforma Pombalina dos estudos Menores no Brasil. In: MAGALDI, Ana Maria; ALVES, Cláudia; GONDRA, José G. (orgs). Educação no Brasil: História, Cultura e Política. Bragança Paulista: EDUSF, 2003.

ANCHIETA. Feitos. São Paulo: [s.n], Livro II versos 825-828, s/d.

AZEVEDO, Fernando de. A Cultura Brasileira. São Paulo: Ed. Melhoramentos, 1964.

BARRETO, Tobias. Estudos Alemães. Aracaju-SE: Ed. do Governo de Sergipe, 1926.

CALÓGERAS, João Pandiá. Os Jesuítas e o Ensino. Rio de Janeiro: Imprensa Nacional, 1911.

CAMPOS, Fernando Arruda. Reflexão introdutória ao estudo da Filosofia na época colonial no Brasil. In: CRIPPA, Adolpho (coord). As ideias filosóficas no Brasil. São Paulo: Convívio, 1978.

. Tomismo e Neotomismo no Brasil. São Paulo: Grijalbo, 1968.

CURY, Carlos R. Jamil. Ideologia e Educação Brasileira. São Paulo: Cortez \& Moraes, 1978.

DEUSDADO, M. A Ferrreira. Educadores Portugueses. Coimbra: [s.n.], 1910.

GRAMSCI, Antonio. Cadernos do Cárcere. Rio de Janeiro: Civilização Brasileira, 2001.v.1

FRANCA, Pe Leonel S. J. Noções de História da Filosofia. Rio de Janeiro: Agir, 1978.

HOORNAERT, Eduardo. História da Igreja no Brasil. Petrópolis: Vozes, 1977.

. A Igreja no Brasil colônia (1550-1800). São Paulo: Brasiliense, 1982.

LEITE, Serafim. História da Companhia de Jesus no Brasil. Lisboa: Livraria Portugália, $1938.10 \mathrm{v}$. 
O curso de Filosofia e as tentativas para se criar a universidade no Brasil no século XVII. Revista Verbum. Rio de Janeiro, v.5, n. 2, p.108-143, abr/mai/jun 1948.

Novas Páginas de História do Brasil. São Paulo: Companhia Editora Nacional, 1965.

MARX, Karl e ENGELS, Friedrich. La sagrada familia - o critica de la critica critica. Buenos Aires: Editorial Claridad, 1973.

MORAES FILHO, Evaristo. O Ensino de Filosofia no Brasil. Decimália, Rio de Janeiro, [s.n.], p.21-25, 1959.

MOURA, D. Odilon. Direções do Pensamento Católico no Brasil no século XX. In: CRIPPA, Adolfo (coord). As ideias filosóficas no Brasil. São Paulo: Convívio, 1978.

PAIVA, José Maria de; BITTAR, Marisa; ASSUNÇÃO, Paulo de (orgs). Educação, História e Cultura no Brasil Colônia. São Paulo: Arké, 2007.

PRIMITIVO, Moacir. A Instituição e o Império - subsídios para a História da Educação no Brasil. São Paulo: Ed. Nacional, 1936-1938.

SENTROUL, Mons. Charles. O que é Philosofia? In: SENTROUL, Mons. Charles. Tratado de Lógica. São Paulo: [s.n.], 1909.

SODRÉ, Nelson Werneck. Síntese de História da Cultura Brasileira. Rio de Janeiro: Civilização Brasileira, 1976.

Notas

${ }^{1}$ Núcleo de Estudos e Pesquisas em História da Educação Brasileira - NEPHEB/HISTEDBR -

Universidade Federal do Estado do Rio de Janeiro (UNIRIO) Email: amsmartins@alternex.com.br

2 Neste texto foram utilizadas edições clássicas de alguns livros que constam da referência bibliográfica, optamos propositalmente em não utilizar edições mais atualizadas dessas obras.

${ }^{3}$ Além da Companhia de Jesus, outras ordens religiosas surgiram no período da Contra-reforma católica: Capuchinhos, Teatinos, Barnabitas e Somascos. Estas ordens foram criadas antes da Companhia de Jesus, no século XVI, elas foram constituídas com um espírito reformador, pois questionavam a conduta pouco cristã das ordens religiosas tradicionais.

${ }^{4}$ O livro do professor Silvestre Pinheiro Ferreira intitulava-se "Preleções Filosóficas sobre a teórica do discurso e da linguagem, a estética, a diceósina e a cosmologia".

Recebido: Agosto-2012

Aprovado: Novembro-2012 